\title{
A PARTICIPAÇÃO POPULAR NA GESTÃO PÚBLICA MUNICIPAL A PARTIR DOS CONSELHOS MUNICIPAIS DE ASSISTÊNCIA SOCIAL
}

\section{THE POPULAR PARTICIPATION IN THE MUNICIPAL PUBLIC MANAGEMENT FROM THE MUNICIPAL COUNCILS OF SOCIAL WELFARE}

\author{
Eliete dos Reis Lehnhart ${ }^{1}$ \\ Rodrigo Cristiano Diehl ${ }^{2}$
}

\section{Resumo}

Este artigo tem por objetivo verificar a importância da participação popular na gestão pública, por meio dos Conselhos Municipais de Assistência Social, na promoção da democracia participativa no espaço público local. Para tanto, a partir de levantamento bibliográfico e pesquisa de campo, buscou-se estudar o poder local na (re)construção dos espaços públicos; delinear os desafios e as perspectivas da participação popular na gestão pública municipal e verificar a percepção da sociedade civil sobre a importância da participação nos Conselhos Municipais de Assistência Social. Para alcançar os objetivos do estudo, por meio de uma pesquisa de campo (modalidade levantamento) de natureza qualitativa e descritiva foi aplicado um questionário online de livre acesso que contou com a participação de sessenta e cinco pessoas. Os principais resultados perpassam pela necessidade de ampliar a divulgação da organização, funcionamento e objetivos dos Conselhos Municipais de Assistência Social como forma de possibilitar a ampliação da participação popular nesses centros decisórios de políticas públicas.

\footnotetext{
${ }^{1}$ Profa Dra. Departamento de Ciências Administrativas da Universidade Federal de Santa Maria (UFSM). Email: elietedosreis@gmail.com

${ }^{2}$ Doutorando e Mestre em Direito pela Universidade de Santa Cruz do Sul (ambos com bolsa Capes). Mestrando em Política Social e Serviço Social pela Universidade Federal do Rio Grande do Sul. Especialista em Gestão Pública Municipal pela Universidade Federal de Santa Maria. Especialista em Direito Constitucional e Administrativo pela Universidade Estácio de Sá. Bacharel em Direito pela Universidade de Santa Cruz do Sul. Bacharelando em Administração Pública pela Universidade Federal do Pampa. Integrante do Observatório do Estado Latino-Americano (ODELA/UFRGS). Integrante do Comitê de Direitos Humanos para a promoção da diversidade cultural (UNISC). Integrante do Núcleo de Estudos e Pesquisas em Saúde e Trabalho (NEST/UFRGS). Integrante do Núcleo de Estudos Políticos e Administrativos (NEPA/UFRGS). Integrante do Grupo de Pesquisa Direito, Cidadania e Políticas Públicas (PPGD/UNISC). Professor e advogado. E-mail: rodrigocristianodiehl@live.com
} 
Palavras-chave: Conselhos Municipais de Assistência Social; democracia participativa; gestão pública; município, participação popular.

\begin{abstract}
This article aims to verify the importance of popular participation in public management, through the Municipal Councils of Social Welfare, in promoting participatory democracy in the local public space. Therefore, based on bibliographical research and field research, we sought to study local power in the (re)construction of public spaces; outline the challenges and perspectives of popular participation in municipal public management; verify the perception of civil society on the importance of participation in Municipal Councils of Social Welfare. In order to reach the study objectives, a qualitative and descriptive field survey (survey modality) was applied to an online questionnaire with sixty-five participants. The main results are related to the need to broaden the dissemination of the organization, operation and objectives of the Municipal Councils of Social Welfare as a way to increase popular participation in these decision-making centers of public policies.
\end{abstract}

Keywords: Municipal Councils of Social Welfare; municipal public management; participatory democracy; popular participation.

\title{
CONSIDERAÇÕES INICIAIS
}

O desenvolvimento do capital social nos espaços públicos e a promoção da participação cidadã nos centros decisórios das sociedades contemporâneas são classificados como imprescindíveis diante do atual cenário de crise política, de ilegitimidade das ações dos governos e de usurpação dos direitos de cidadania. A ampliação do capital social deve ser compreendida neste trabalho enquanto pressuposto de ações democráticas e da própria efetivação da participação popular nos centros decisórios da sociedade.

O favorecimento da corresponsabilidade dos cidadãos em suas comunidades assume 0 objetivo de instigar e de possibilitar à construção de uma nova cultura de participação ativa nos processos emancipatórios, afetando diretamente a gestão pública municipal e o poder local no que se refere as suas estratégias e ações para o enfrentamento das questões sociais por meio de um conjunto, coordenado e interligado, de políticas públicas. 
A instauração de modelos flexíveis e participativos deve ser construída para possibilitar a criação e a (re)estruturação de espaços comuns, no qual os usuários e demais interlocutores das decisões e de ações públicas possam dialogar e encontrar melhores saídas para as demandas sociais. É diante desse cenário que as relações partilhadas entre Estado, sociedade civil e mercado passam por uma reformulação e mudança no conceito e aplicação da participação popular tanto dentro quanto fora de suas instituições e de seus agentes.

Com o pleno funcionamento dos Conselhos Municipais e com a participação ativa da sociedade, acaba-se por empoderar a governança local, na definição de um elo entre o governo local e a sociedade sob a ótica democrática. A participação popular na gestão pública municipal deve ser compreendida como um meio essencial na construção, implementação e avaliação de políticas públicas, promovendo o fortalecimento da cidadania, com o aumento do nível de democracia nas decisões e o controle mais rigoroso dos recursos públicos.

Contudo, um dos principais desafios à democracia participativa está aquele voltado a garantir e a concretizar a gestão pública municipal como um espaço democrático de diálogo entre governo e cidadão, até porque, o município se apresenta como o ente da federação mais próximo aos indivíduos. Por isso, a ampliação e a conscientização da participação popular no debate em todos os ciclos das políticas públicas é fundamental, especialmente quando analisada a atuação dos Conselhos Municipais de Assistência Social.

Tendo por base a realidade brasileira no que se refere a participação popular nos conselhos nas esferas federais, estaduais e municipais, questiona-se: "a participação popular na gestão pública municipal, por meio dos Conselhos Municipais de Assistência Social, mostra-se importante para a promoção da democracia participativa no espaço público local?"

Diante desse cenário, o presente estudo tem por objetivo verificar a importância da participação popular na gestão pública, por meio dos Conselhos Municipais de Assistência Social, na promoção da democracia participativa no espaço público local. Para tanto pretendese: I) estudar o poder local e a (re)construção dos espaços públicos; II) delinear os desafios e as perspectivas da participação popular na gestão pública municipal; III) verificar a percepção da sociedade civil sobre a importância, ou não, da participação nos Conselhos Municipais de Assistência Social.

O presente estudo se justifica pela necessidade de aprofundamento e disseminação das discussões acerca da temática da participação popular na gestão pública municipal por meio dos Conselhos Municipais, especialmente nos dias atuais, onde a democracia está sendo 
novamente colocada em xeque por movimentos contrários a todo um processo de luta democrática que a sociedade brasileira promoveu nas últimas décadas.

Para responder o problema de pesquisa e atingir o objetivo proposto, o presente trabalho está estruturado em mais cinco seções, além da introdução: na seção dois aborda-se o referencial teórico que balizou a realização deste estudo. Na seção três são apresentados os procedimentos metodológicos que possibilitaram a operacionalização da pesquisa. Na seção quatro são apresentados os resultados alinhados com os objetivos propostos. Na seção cinco são abordadas as considerações finais e por fim as referências utilizadas no estudo em questão, assim como, em anexo, o questionário aplicado.

\section{REFERENCIAL TEÓRICO}

\section{O poder local na (re)construção dos espaços públicos}

Espaço público, espaço público estatal, espaço público social, espaço comunitário, espaço social, enfim, independentemente do termo utilizado a sua importância para as sociedades modernas encontra-se em todas elas, essencialmente, quando prevê-se a (re)definição desse espaço enquanto uma arena de confluência de posições e de interesses, direta ou indiretamente ligados ao Estado (HERMANY, 2012). Contudo, dentro dessa arena deve ocorrer o respeito a diversidade cultural, enquanto elemento essencial na (re)construção desses espaços no poder local, no qual são tão necessários para a convivência harmônica em sociedade.

O que se busca é a (re)construção dos espaços públicos como uma transformação do indivíduo e do meio social a partir de práticas comprometidas com a emancipação do sujeito ao possibilitar a participação de todos os cidadãos nos processos decisórios e na efetivação de políticas públicas que visem garantir e concretizar direitos. Quanto maior for a possibilidade de participação e, por consequência, a efetiva participação do cidadão nos rumos da sua comunidade, melhor será a qualidade do espaço público em que ele está inserido (PERUZZO, 1998).

A nova cidadania, calcada no indivíduo e em sua relação com a sociedade, que se visualiza no espaço público mostra-se na condição de um processo histórico de construção da própria dignidade humana em seus princípios basilares, cabendo à polis, por intermédio da lei (nomos) a criação das necessárias condições para que seja possível o estabelecimento de uma 
ordem de equidade (CORRÊA, 2010). Sob tal prisma, a inclusão social por meio da efetivação da cidadania passa a configurar como o construto convencional de coletividade tendo por base decisões conjuntas que visem a igualdade de oportunidades a todos os cidadãos.

A busca por novos espaços públicos de construção do poder, como é o caso do espaço local de participação cidadã, não acarreta a negação das demais esferas, inclusive no caso de compreensão de sua importância no cenário atual, mas sim a possibilidade que se dê uma atenção especial a existência de outros espaços, retirando o foco do binômio crise do Estado versus processo de globalização. O espaço público local deve ser concebido como um espaço simples, sem muitas formalidades, todavia eficaz na participação social ao possibilitar tanto a manifestação dos interesses da comunidade quanto a produção de instrumento de regulamentação do controle social via participação popular (HERMANY, 2012).

Nessa conjuntura da participação social enquanto um exercício de poder, salientam-se os ensinamentos de Foucault (2009) que, de acordo com o pensamento do autor, o poder estaria centrado no estabelecimento das relações entre os saberes - cada um considerado como possuindo positividade específica, a positividade do que foi efetivamente dito e deve ser aceito como tal e não julgado a partir de um saber posterior e superior - para que destas relações surjam, em uma mesma época ou em épocas diferentes, compatibilidades e incompatibilidades que não sancionam ou invalidam, mas estabelecem regularidades, permitem individualizar formações discursivas.

Este espaço público propício para a participação popular, denominado de espaço local (em inglês: local authority e em francês: communautés locales), encontra-se em pleno processo de emergir com a finalidade de se tornar uma das questões basilares da própria organização das sociedades modernas. Para Dowbor (2008), o poder local situa-se exatamente no centro de toda a conjuntura de transformações sociais, econômicas e políticas que devem ocorrer a partir da lógica da descentralização, da desburocratização e da participação na gestão pública municipal.

Somente uma descentralização efetiva, na qual o cidadão realmente possa participar dos centros decisórios, dos projetos de planejamento e da gestão de políticas públicas é que se promoverá a inclusão social. Nesse caminho a ser percorrido pelas comunidades, o princípio da subsidiariedade, o qual será compreendido na sequência do estudo, coaduna perfeitamente enquanto um espaço privilegiado na mediação do diálogo entre a sociedade civil e o Estado (esse último compreendido aqui como sociedade civil mais sociedade política igual ao Estado) (DOWBOR, 2008). 
A esfera pública apresenta-se como o espaço propício para o debate jurídico entre os diversos atores sociais locais, enquanto processo de aperfeiçoamento da democracia ao possibilitar o diálogo como forma de construção dos rumos da humanidade. Esse espaço autônomo é compreendido por dois lados, segundo Vieira (2001): de um lado tem-se o desenvolvimento dos processos de formação democrática da opinião pública e, portanto, da vontade política da coletividade, e por outro lado, na transformação de uma cidadania passiva para uma cidadania ativa com a transformação da sociedade civil numa instância deliberativa local e legitimadora do poder político.

Essa necessidade de construção de espaços públicos participativos mostra-se especialmente possível no âmbito local, não há dúvidas que a proximidade do cidadão com os problemas e as demandas sociais da sua comunidade provoque maior disposição por sua parte em participar, uma vez que, ao verificar que a sua participação possibilita a construção de políticas públicas de inclusão social, esse processo de participação acaba sendo natural e contínuo. Nesse cenário, o governo local tem se mostrado ciente de suas obrigações para com a população especialmente no incentivo à participação cidadã como tem-se verificado nos últimos anos (ORDÓÑEZ, 2005).

Desse modo, como a busca pela cooperação na compreensão enquanto um mecanismo de superação tanto das barreiras naturais quanto dos problemas sociais sempre esteve na agenda dos indivíduos, a cooperação atualmente é visada como forma de os grupos sociais usufruírem mais das ações desenvolvimento nas sociedades (SOUZA, 2014). O que não se pode admitir nesse processo de participação no espaço local, é que ela se transforme em uma cooperação da manufatura ou em uma cooperação da indústria, nas quais ambas encontram-se a serviço do capital e situam-se aquém da proposta inicial.

O importante é reconhecer e compreender o outro em sua cultura, inclusive na possibilidade de juntos construir espaços públicos de participação que deva pautar todo o esforço no elo entre a identidade e a instrumentalidade a partir de uma concepção do sujeito, ao mesmo tempo, autônomo e coletivo. Assim, para que seja possível o estabelecimento da comunicação entre os atores sociais da comunidade local mostra-se necessário compreender inclusive os seus atos e suas linguagens como forma de reconhecimento (TOURAINE, 1998).

O espaço público deve ser (re)pensado e (re)construído como um local propício à interação intersubjetiva de cidadãos conscientes, solidário e participativos, sem a filiação de visões liberais ou republicanas, isto é, um espaço neutro no qual prevaleça a possibilidade de políticas públicas de inclusão social construídas com o apoio e a participação ativa do cidadão. 
Somente a partir dessas premissas é que será possível institucionalizar o espaço público na pluralidade das comunidades locais modernas e a chance de lograr êxito na construção do consenso utilizando procedimentos comunicativas na gestão pública (VIEIRA, 2001).

O que se busca é a instituição de um espaço público próximo ao cidadão como um local vital e indispensável para a convivência humana ao possibilitar o indivíduo construir, de forma consciente e criativamente, sua identidade, seus projetos de vida e seus sonhos. De acordo com Corrêa (2010), o poder público local tem relação direta com as condições externas, que influência todas as pessoas que ali residem, respeitadas as suas diferenças e peculiaridades. Essa nova concepção deve valorizar a política enquanto uma dimensão público-estatal, sem se olvidar das condições materiais de existência e as condições econômicas que juntas integram o espaço público.

Permeia o próprio conceito de espaço público a partir da (re)construção pelo poder local, as virtualidades do processo democrático de forma mais aberta e popular, na qual, com a expansão da imaginação criativa, de acordo com Bonavides (2008), será possível (re)construir e (re)definir a consciência dos cidadãos sobre as suas ações na gestão pública municipal. Com base nessas premissas, será possível a inclusão de novos instrumentos de participação popular, uma vez que a supremacia da intermediação clássica e a representação político como hoje se conhece encontra-se com a sua decadência irremediável.

É na (re)construção desse novo espaço público local que será possível, por um lado aos cidadãos participar, decidir, acompanhar, executar e fiscalizar as políticas públicas de inclusão social e, por outro lado, a promoção do fortalecimento da cidadania ao criar instrumentos de participação social na gestão pública. Assim, com essa redefinição também se encontrará um ambiente fértil a sua expansão, no momento que, os indivíduos passam a adquirir e a consolidar novos direitos e ampliam sua participação na criação do próprio direito (DIEHL; COSTA, 2015).

Nesse contexto, a participação popular e do próprio poder local na (re)construção dos espaços públicos é essencial, especialmente quando trata-se da promoção da inclusão social por meio de políticas públicas. Porém, também devem ser analisadas as perspectivas e os desafios, dentro deste cenário, da democracia participativa e seus reflexos na contemporaneidade. Diante desse contexto o próximo capítulo é estruturado. 


\section{Participação popular e democracia participativa}

Compreender a origem e o significado etimológico da palavra participação: do latim participatio.onis, qual seja, ação ou efeito de participar, fazendo parte de alguma determinada coisa torna-se relevante dentro do contexto social atual, de tal modo que participar possibilita a construção conjunta de mecanismos e instrumentos de aperfeiçoamento da convivência dos cidadãos em sociedade (MICHAELIS, 2015).

Segundo Machado (2016), além de possibilitar a presença em determinado espaço/local, a participação está direcionada às reais condições de influenciar no diálogo e na construção de uma determinada temática, utilizando para isso processos desde já construídos coletivamente. No que se refere a esfera da gestão pública, de acordo com Peluffo (2005), os autores que expõem sobre a necessidade de participação dos cidadãos ou dos habitantes de um Estado no exercício do poder público (aqui compreendido enquanto todas as formas de construção e de aperfeiçoamento da sociedade), costumam adotar conceitos diversos sobre o processo de construção da relação entre poder local e cidadão segundo o local de aplicação da participação popular e de sua população diretamente atingida.

Uma forma de colocar em prática a participação popular pode ser por meio do planejamento descentralizado, no qual as demandas ordenadas são submetidas para a comunidade que ficará incumbida de pronunciar-se, respeitando assim, a liberdade individual e social e não a livre decisão de uma empresa, por exemplo, de instalar uma fábrica de produção de algum material prejudicial à comunidade que ali reside e vive (DOWBOR, 2008).

Para Demo (1988), a participação social tem por finalidade central sete pontos, a saber: I) a autopromoção; II) a realização da cidadania; III) a definição das regras do jogo; IV) o controle do poder; V) a moderação da burocracia; VI) a prática da negociação e; VII) a construção de uma cultura efetivamente democrática. Desse modo, a participação social pretende proporcionar o apoio necessário (nova legitimidade) a setores da sociedade tradicionalmente fechados, separados dos cidadãos, com o objetivo de superar a segregação entre Estado e sociedade civil, para que os indivíduos possam expressar diretamente suas demandas e controlar decisões que os influenciam diretamente (ORDÓÑEZ, 2005).

Contudo, deve-se ter consciência de que a participação é um processo social que existe independente da interferência provocada por qualquer agente externo. A participação é o próprio processo de criação do homem ao pensar e agir sobre os desafios da natureza e sobre os desafios sociais, nos quais ele próprio está situado. Essa participação, enquanto mecanismo 
basilar de qualquer democracia, ao ser refletida e enfrentada por todos os atores sociais atingidos direta ou indiretamente pelas políticas públicas, deve ser concebida não como uma política de reprodução da ordem imposta, mas sim, uma questão social (SOUZA, 2014).

Para Garrison (2000), a participação popular deve ser vista não somente como um mecanismo com a finalidade de melhorar a eficácia do desenvolvimento dos serviços públicos, mas também, como o instrumento-chave na garantia da sustentabilidade e alavancagem a longo prazo da sociedade. Importante ressaltar que cabe ao governo, por meio de um projeto coletivo de construção e não "por decreto", a definição das prioridades de atuação e que essa definição atinge tanto as gerações presentes quanto as futuras.

Oriundas da questão social, as transformações que estão ocorrendo na contemporaneidade são construídas a partir de um pilar fundante: o poder local. Esse fenômeno deriva do fato de que, as comunidades dentro das cidades se organizam em busca de um resultado final, ou seja, em busca de qualidade de vida, na qual o conjunto do processo passa a ter âncora e, ao mesmo tempo, sentido. Assim, segundo Dowbor (2008), descentralização, planejamento municipal, diversidade de sistemas de participação das comunidades nas decisões do espaço de vida do cidadão são elementos constitutivos do "poder local".

A democracia participativa na gestão pública municipal, segundo Grüne (2012), incentiva a participação do cidadão não apenas sobre aquilo que diz respeito a ele próprio, mas também sobre questões concernentes a outras pessoas e a toda comunidade. Em todos os casos, seja na ampliação ou na restauração da democracia, há também um processo de redefinição do seu significado cultural, ou melhor, de seu significado enquanto gramática social vigente. Desta forma, a democracia participativa inicia com a tentativa de estabelecer o significado de determinadas práticas, uma vez que a tentativa de ampliação da chamada gramática social ocorre com a incorporação de novos atores sociais ou novos temas à política (SANTOS; AVRITZER, 2003).

Os recentes processos de (re)democratização também introduziram em suas bases a participação. Entendida como a participação direta na tomada de decisões e em seu controle, vez que se está sob uma nova fase da democracia, é possível e necessário que o movimento comunitário avance e influencie diretamente, de forma a apresentar propostas que sejam discutidas e estabelecidas pelo movimento sobre as principais demandas da sociedade.

Essa ideia de democracia participativa era central no pensamento e nas práticas e políticas de Gandhi, inspirando muitos ativistas do movimento denominado de libertação. 
Segundo Santos e Avritzer (2003, p. 113), Gandhi estruturava o seu pensamento por meio dos conceitos de "[...] swaraj (autogoverno) e de swadeshi (controle comunitário sobre os recursos) e pela invocação da imagem de república-aldeia (gram swaraj)" que era caracterizado como o representante da tradição democrática indiana.

Portanto, a democracia parece ser intrinsecamente dinâmica, uma vez que gera movimentos sociais encorajados devido à frustração com a característica pouco democrática da prática atual das instituições, já incluídos os limites de exclusão e inclusão, "[...] porque seus vários postulados são, com frequência, contraditórios, possibilitando a diversos movimentos reivindicarem a bandeira democrática" (MARKOFF, 2013, p. 29). Também, para o autor, devido aos detentores do poder considerarem útil afirmar que os arranjos políticos que os sustentam no comando são democráticos.

A democracia participativa, na concepção de Bonavides (2008), possibilita o enfrentamento à conspiração desagregadora do neoliberalismo e as novas formas e ideais de organização do capital. Porém, não há democracia sem participação, na qual a sorte é que a participação popular direciona para as forças sociais que vitalizam diariamente a democracia, fornecendo-Ihe um grau de eficácia e de legitimidade dentro do quadro social das relações de poder (interesses) na sociedade já repartida pelo processo de globalização.

Com a promulgação da Constituição Federal de 1988, introduziu-se no Brasil mecanismos de participação dos cidadãos nas tomadas de decisões. De acordo com Anduiza e Bosch (2007), esses instrumentos podem ser divididos em: eleitoral/não eleitoral, convencional e não convencional e voz/saída. O primeiro deles, a eleitoral/não eleitoral, é compreendida como a participação essencial e perfeitamente integrada na estrutura institucional das democracias representativas, como é o caso brasileiro.

O segundo, convencional/não convencional, tem relação com a construção de novos mecanismos de participação não convencionais ou fora da participação eleitoral direta, como por exemplo: ocupação de prédios, greves, manifestações, entre outras. E o terceiro, voz/saída, mesmo relacionando-se entre si, há pequenas diferenças: na qual a voz refere-se a possibilidade de comunicar o descontentamento com o sistema, seja por meio de organizações, partidos, associações e a saída na possibilidade de exercer pressão por meio da ameaça de não ir, seja, não ir votar, abandonar um partido, deixar de comprar um determinado produto, entre outros (ANDUIZA; BOSCH, 2007).

Dentro da participação não eleitoral, mas com um caráter institucionalizado, encontrase os conselhos municipais ou conselhos gestores de políticas públicas enquanto espaços 
propícios que possibilitem dar voz aos cidadãos dentro das suas temáticas. Por exemplo: dar voz aos cidadãos dentro dos Conselhos Municipais de Assistência Social em matérias que sejam de competência desse conselho, assim como dar voz nas temáticas dos Conselhos de Saúde, de Segurança Pública, da Criança e do Adolescente, do Idoso, entre tantos outros possíveis exemplos.

Destaca-se que este estudo faz referência aos Conselhos Municipais de Assistência Social, os quais serviram de base, diante de uma determinada semelhança em seu funcionamento e estrutura dada pela Lei n. 8.742/1993, para a análise dos dados da pesquisa. Esses conselhos podem ser estruturados como novos espaços públicos de participação da sociedade civil na gestão da coisa pública e na proteção social, demonstrando o seu caráter de elemento diferencial da introdução da nova forma de governança municipal. Assunto este estudado na próxima seção.

\section{A promoção e o aperfeiçoamento da democracia participativa no espaço público por meio dos Conselhos Municipais de Assistência Social}

Desde os tempos de Aristóteles, as deliberações na sociedade são construídas como oportunidades de promoção da participação dos indivíduos nas decisões e nos rumos de sua comunidade. O cidadão nessa época era compreendido enquanto uma parte essencial das cidades, tendo assegurado o direito a participar para que fosse assegurada a sua vida de forma independente. Contudo, é importante ressaltar que, mulheres, negros e estrangeiros não detinham essa possibilidade, uma vez que não thes era reconhecido o reclamo legítimo (ARISTÓTELES, 1985).

Com o passar dos séculos e a evolução tanto dos cidadãos quanto das sociedades, o processo de participação passou por uma ampliação e o rechaço as suas restrições, pelo menos formalmente. Desse modo, no caso brasileiro, a partir dos anos 80 (período da redemocratização) iniciou a formação de uma nova relação entre Estado e sociedade civil, com a finalidade de, segundo Neves (2008), promover dois aspectos: a democratização do Estado com processos participativos e a politização da sociedade civil, especialmente na gestão das políticas públicas.

Dentre desses processos participativos na sociedade brasileira encontra-se os conselhos municipais na condição de instrumentos de redemocratização da gestão pública local e de, inclusive, ampliação da eficiência e da efetividade das políticas sociais setoriais em razão, tanto 
da construção, quanto do controle estar sendo realizado pelos cidadãos. Com a sua disseminação no território nacional, segundo Ribeiro, Azevedo e Santos Jr. (2004), é possível verificar os conselhos, especialmente os municipais, como uma nova instância de deliberação local, transformando os padrões até então instituídos de gestão das políticas públicas.

A definição oficial para os conselhos municipais, de acordo com o Portal da Transparência (BRASIL, [s.d.) declara que conselhos gestores de políticas públicas são: canais efetivos de participação, que permitem estabelecer uma sociedade na qual a cidadania deixe de ser apenas um direito, mas uma realidade. A importância dos conselhos está no seu papel de fortalecimento da participação democrática da população na formulação e na implementação de políticas públicas. Entretanto, mesmo diante da importância dos conselhos no âmbito local, a participação social encontra-se invisível para a grande massa populacional, o que acaba por provocar um esvaziamento e, por consequência, a perda de legitimidade enquanto um processo eminentemente democrático.

Nesse processo, a informação, o conhecimento e a ação podem ser classificadas como condições necessárias para o exercício do poder, na qual, a participação democrática e cidadã detém como pressuposto o poder em termos de gestão compartilhada. Contudo, caso não o realize "[...] estará apenas manipulando-se pessoas e grupos de forma a controlá-las, e não o contrário, o conselho participando da elaboração e controlando a execução das políticas públicas" (GOHN, 2004, p. 89).

Com a consolidação dos conselhos municipais como uma nova arena políticoadministrativa espera-se que ocorra a reconfiguração dos procedimentos decisórios no poder local, iniciando com a fase da definição do problema social e a busca por seu enfrentamento, passando pela formulação de políticas e chegando até a implementação e o controle dessas ações (GOHN, 2004). Com isso, deve-se fortalecer a capacidade dos cidadãos e da sociedade de controlar os instrumentos e os critérios de uso dos próprios recursos públicos, ao mesmo tempo que, promove decisões mais democráticas e em busca do bem estar social (RIBEIRO; AZEVEDO; SANTOS JR, 2004).

Ainda que com grandes dificuldades, especialmente econômicas, os conselhos municipais realizam funções de intermediação entre o governo e a sociedade em um processo de legitimação de todos os atores sociais na construção de políticas públicas ao possibilitar o reconhecimento dos problemas sociais do poder local e de suas expectativas de enfrentamento. Portanto, os conselhos gestores estão constituindo-se em arenas de integração na qual toda a sociedade civil é convidada para dialogar e buscar soluções conjuntas aos problemas sociais. 
Segundo Ribeiro, Azevedo e Santos Jr. (2004), com essa participação popular, a eficácia e a efetividade das políticas públicas locais de atendimento às demandas sociais aumenta.

A participação popular pode ser traduzida, de acordo com Dias (2007, p. 46), como um "[...] processo político concreto que se produz na dinâmica da sociedade". Tratando-se de um processo que encontra-se intrinsicamente ligado ao aperfeiçoamento da democracia participativa, na qual a participação do cidadão em conselhos municipais, especialmente nos Conselhos Municipais de Assistência Social, de caráter essencialmente deliberativo e fiscalizador, é primordial na construção, implementação e fiscalização de políticas públicas.

Para que fosse possível o exercício dessa função, pelo menos em nível normativo, sem aqui ingressar na precariedade das estruturas físicas e a falta de pessoal disponibilizadas aos Conselhos, é fundamental a composição igualitária conforme disciplina a Lei n. 8.742/1993. Isto é, para cada conselheiro representante do governo, haverá um representante da sociedade civil, como por exemplo, se um Conselho tiver catorze conselheiros, sete serão indicados pelo governo e sete representarão a sociedade civil. Contudo, há a previsão de exceções em outros Conselhos, tais como na saúde e na segurança alimentar.

Ainda, segundo a Lei n. 8.742/1993 que dispõe sobre a organização da Assistência Social e dá outras providências, em seu artigo dezesseis afirma que as instâncias deliberativas do Sistema Único de Assistência Social - SUAS, de caráter permanente e composição paritária entre governo e sociedade civil, são: I - o Conselho Nacional de Assistência Social; II - os Conselhos Estaduais de Assistência Social; III - o Conselho de Assistência Social do Distrito Federal; IV - oS Conselhos Municipais de Assistência Social (BRASIL, 1993).

Outro ponto que deve ser observado, é em relação a estruturação desses Conselhos, no qual, segundo o parágrafo único do artigo dezesseis da referida lei, os Conselhos de Assistência Social estão vinculados ao órgão gestor de assistência social, que deve prover a infraestrutura necessária ao seu funcionamento, garantindo recursos materiais, humanos e financeiros, inclusive com despesas referentes a passagens e diárias de conselheiros representantes do governo ou da sociedade civil, quando estiverem no exercício de suas atribuições (BRASIL, 1993).

Portanto, são fundamentais e obrigatórios para que haja o repasse aos Municípios, Estados, Distrito Federal dos recursos previstos na legislação, o funcionamento: I - Conselho de Assistência Social, de composição paritária entre governo e sociedade civil; II - Fundo de Assistência Social, com orientação e controle dos respectivos Conselhos de Assistência Social; III - Plano de Assistência Social (BRASIL, 1993). 
Os conselhos municipais encontram na legislação o seu respaldo de estruturação e funcionamento, contudo, os problemas começam a surgir em sua efetivação. A superação desses desafios para os conselhos municipais somente poderá ser eficaz, no momento que, se acentuar o seu papel no controle social das políticas públicas. Esse controle não pode ser visto meramente como uma fiscalização dos atos do Executivo, mas sim, por meio de avaliações permanente e comparação de dados. Esses elementos são necessários para que a sociedade em geral visualize a importância dos conselhos municipais e de sua participação ativa, proporcionando uma (re)significação do sentimento de pertencimento de comunidade e de garantia do direito/dever de cidadania.

A participação social pode ser ampliada e consolidada não somente com a eleição de conselheiros, mas também, por meio de mecanismos não institucionais, como a realização de fóruns, comissões, eventos, entre outros, no espaço público, além da própria atuação independente das entidades no que se refere a mobilização, a pressão, ao debate público e, inclusive, a interação com os meios de comunicação na condição de difusores de ideias democráticas.

\section{PROCEDIMENTOS METODOLÓGICOS}

O presente estudo é de natureza qualitativa e descritiva na qual, de acordo com Minayo (2007), questões mais particulares são compreendidas, preocupando-se em um nível de realidade que a pesquisa quantitativa não pode ser utilizada. Portanto, a pesquisa qualitativa trabalha com um universo de significados, motivos, aspirações, valores, entre outros, que caracterizam-se por ser um espaço mais profundo das relações, dos processos e fenômenos.

Corroborando com as ideias de Minayo (2007), encontra-se Triviños (1987), para quem na pesquisa qualitativa realizam-se escolhas de assunto e/ou problemas a serem estudados a partir da coletiva e análise de dados e informações. Assim, diferentemente do que ocorre na pesquisa quantitativa, aqui não será exigido definir variáveis e medi-las, mas apenas descrevêlas.

A utilização do tipo descritivo se dá em razão da necessidade de descrever as características de uma população, um fenômeno ou experiência para o estudo realizado. Assim, a pesquisa descritiva, de acordo com Triviños (1987), exige do investigador uma gama de informações sobre o que se deseja pesquisa, para que seja possível a análise correta de fatos e fenômenos de determinadas realidade. 
Em relação à estratégia de pesquisa, este estudo se caracteriza como uma pesquisa bibliográfica e documental e de campo (pesquisa de levantamento). A pesquisa documental é realizada em fontes primárias, ainda não trabalhadas, como por exemplo, legislação. Já a pesquisa bibliográfica é realizada através do levantamento de referências já analisadas e publicadas em meios eletrônicos e físicos.

A pesquisa de campo, na modalidade levantamento, objetiva a obtenção do conhecimento direto da opinião dos pesquisados sobre determinado fato que, neste estudo, centra-se na relevância/importância da participação popular nos Conselhos Municipais de Assistência Social (FONSECA, 2002).

Para a coleta de dados da pesquisa, foram utilizadas duas fontes de evidência: a análise bibliográfica e documental, está última especialmente na Lei n. 8.742/1993, que dispõe sobre a organização da Assistência Social e dá outras providências, e um questionário online disponibilizado na internet, especialmente em redes sociais, durante o período de 16.05 .2018 a 27.05.2018, que contou com duzentos e sessenta e sete cliques no link da pesquisa, mas com participação efetiva de sessenta e cinco pessoas.

Os dados obtidos com a aplicação do questionário serão analisados com base na Análise Temática de Conteúdo que, de acordo com Minayo (2007), se subdivide em três etapas: I) a pré-análise, II) a exploração do material ou codificação e III) o tratamento dos resultados obtidos/interpretação.

O questionário foi elaborado com base no referencial teórico adotado e foi estruturado em duas partes. A primeira parte contava com cinco questões sobre o perfil dos respondentes e a segunda com nove questões sobre aspectos do Conselhos Municipais de Assistência Social. As questões específicas da temática eram abertas, com o intuito de coletar maiores informações referentes a importância da participação popular na gestão pública por meio dos Conselhos.

Segundo Malhotra (2006), as pesquisas realizadas no modelo online, isto é, com o auxílio da internet, estão ficando cada vez mais populares diante de seus inúmeros benefícios, entre eles: menores custos, rapidez, capacidade de atingir um maior número de pessoas e/ou determinados grupos. Inclusive, do ponto de visto dos respondentes, esse instrumento é o mais conveniente, uma vez que o possibilita responder no tempo e local de cada um.

A aplicação do questionário online foi aberto a qualquer pessoa interessada na temática. Dessa forma, a amostra constituiu-se em não probabilística e por conveniência. A partir do retorno do questionário, percebeu-se que em grande parte dos respondentes da 
pesquisa estavam vinculados ao Serviço Social e a Ciência Jurídica, uma vez que são áreas de atuação do pesquisador, o que não compromete a qualidade do estudo.

Os dados foram analisados de forma descritiva, a partir de três blocos de questões que compuseram o questionário online (Figura 01): 1) cinco perguntas estavam relacionadas com o levantamento de questões sobre o perfil dos respondentes; 2) quatro questões sobre o conhecimento acerca de algum conselho municipal de políticas públicas ou do próprio Conselho Municipal de Assistência Social e, por fim; 3) cinco questões que objetivavam levantar a percepção sobre a importância da participação popular nos CMAS.

Figura 01: Composição do questionário

\begin{tabular}{|c|c|c|}
\hline BLOCO 01 & BLOCO 02 & BLOCO 03 \\
\hline $\begin{array}{l}\text { Você é? (Gestor } \\
\text { público, } \\
\text { conselheiro, } \\
\text { membro da } \\
\text { sociedade) }\end{array}$ & $\begin{array}{c}\text { Você conhece algum } \\
\text { Conselho Municipal de } \\
\text { Assistência Social - CMAS? }\end{array}$ & $\begin{array}{l}\text { Em uma escala de } 0 \text { (zero) a } 10 \text { (dez) estrelas, } \\
\text { considerando } 0 \text { (zero) como nenhuma } \\
\text { relevância e } 10 \text { (dez) como total relevância, } \\
\text { para você qual o nível de importância da } \\
\text { participação popular nos Conselhos } \\
\text { Municipais de Assistência Social? }\end{array}$ \\
\hline Gênero & $\begin{array}{c}\text { Você participa ou } \\
\text { acompanha as reuniões } \\
\text { de algum CMAS? }\end{array}$ & $\begin{array}{c}\text { Para você, quais são as maiores dificuldades } \\
\text { para a participação popular nos CMAS? }\end{array}$ \\
\hline Faixa etária & $\begin{array}{l}\text { Se você respondeu "sim" } \\
\text { na questão anterior, há } \\
\text { quanto tempo participa } \\
\text { ou acompanhada as } \\
\text { reuniões? }\end{array}$ & $\begin{array}{c}\text { Para você, quais medidas/ações deveriam ser } \\
\text { tomadas para ampliar a participação popular } \\
\text { nos CMAS? }\end{array}$ \\
\hline Escolaridade & $\begin{array}{l}\text { Você teria interesse em } \\
\text { conhecer e participar de } \\
\text { algum CMAS? }\end{array}$ & $\begin{array}{c}\text { Como você avalia a atuação dos CMAS, } \\
\text { especialmente na publicização das } \\
\text { informações das reuniões? }\end{array}$ \\
\hline Profissão & 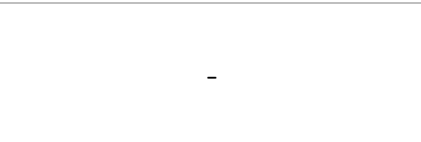 & $\begin{array}{c}\text { Você considera os conselhos municipais } \\
\text { como espaços importantes para o exercício } \\
\text { da cidadania? Por quê? }\end{array}$ \\
\hline
\end{tabular}

Fonte: elaborado pelo autor.

\section{RESULTADOS}

A apresentação dos resultados levantados por meio da aplicação e retorno de 65 (sessenta e cinco) questionários divide-se em duas partes. Na primeira, apresenta-se uma descrição pormenorizada sobre o perfil dos pesquisados (idade, gênero, escolaridade e profissão) e, na segunda, verifica-se a percepção desses em relação a relevância/importância da 
participação popular nos Conselhos Municipais de Assistência Social, observando-se especialmente os seus desafios e as perspectivas.

\section{Perfil dos pesquisados}

Os questionamentos a seguir eram de resposta obrigatória para a finalização do questionário. Quanto ao gênero, conforme observado na Tabela 01 abaixo, dos sessenta e cinco pesquisados, cinquenta e quatro são do gênero feminino e onze do gênero masculino (nenhum respondente marcou a opção outros).

\section{Tabela 01: Gênero}

\begin{tabular}{|c|c|c|}
\hline & Frequência & Percentual \\
\hline Feminino & 54 & $83,1 \%$ \\
\hline Masculino & 11 & $16,9 \%$ \\
\hline Outros & 0 & $0 \%$ \\
\hline Total & 65 & $100 \%$ \\
\hline \multicolumn{2}{|c|}{ Fonte: dados da pesquisa. }
\end{tabular}

Dentre aqueles que responderam ao questionário, há uma diferença se comparado a divisão dos gêneros na sociedade brasileira, do total de 203,2 milhões de brasileiros, 98,419 milhões são homens e 104,772 são mulheres, o que representa 48,4\% e 51,6\%, respectivamente. Já de acordo com os dados acima levantados, a pesquisa teve uma participação majoritária de pessoas do gênero feminino com 54 contra 11, o que representa $83,10 \%$ e $16,9 \%$ respectivamente.

Na tabela 02, observa-se a faixa idade dos participantes da pesquisa.

Tabela 02: Faixa etária

\begin{tabular}{|c|c|c|}
\hline & Frequência & Percentual \\
\hline Menos de 18 anos & 0 & $0 \%$ \\
\hline De 18 a 24 anos & 10 & $15,4 \%$ \\
\hline De 25 a 35 anos & 27 & $41,5 \%$ \\
\hline De 36 a 45 anos & 18 & $27,7 \%$ \\
\hline
\end{tabular}




\begin{tabular}{|c|c|c|}
\hline De 46 a 55 anos & 7 & $10,8 \%$ \\
\hline De 56 a 65 anos & 3 & $4,6 \%$ \\
\hline Mais de 66 anos & 0 & $0 \%$ \\
\hline Total & 65 & $100 \%$ \\
\hline
\end{tabular}

Fonte: dados da pesquisa.

Conforme dados apresentados, a pesquisa teve maior participação de pessoas na faixa etária de vinte e cinco a trinta e cinco anos, o que representou $41,5 \%$ dos entrevistados. Não houve nenhuma participação de pessoas com mais de sessenta e seis anos e crianças ou adolescentes na pesquisa e, caso houvesse na primeira faixa etária (menores de dezoito anos), essa seria desconsiderada por razões legais.

Por sua vez, a Tabela 03 retrata a escolaridade dos membros da pesquisa. Foram considerados para fins de exatidão tanto a formação concluída quanto a formação em andamento.

Tabela 03: Escolaridade

\begin{tabular}{|c|c|c|}
\hline & Frequência & Percentual \\
\hline Sem escolaridade & 0 & $0 \%$ \\
\hline Ensino fundamental incompleto & 0 & $0 \%$ \\
\hline Ensino fundamental completo & 0 & $0 \%$ \\
\hline Ensino médio incompleto & 0 & $0 \%$ \\
\hline Ensino médio completo & 1 & $1,5 \%$ \\
\hline Curso técnico & 0 & $0 \%$ \\
\hline Ensino sup. Incompleto/andamento & 8 & $12,3 \%$ \\
\hline Ensino superior completo & 20 & $30,8 \%$ \\
\hline Pós-graduação (especialização, mestrado e/ou doutorado) & 36 & $55,4 \%$ \\
\hline Total & 65 & $100 \%$ \\
\hline
\end{tabular}

Fonte: dados da pesquisa.

Em relação a escolaridade dos respondentes, a grande maioria, cinquenta e seis pessoas (o que representa 86,2\%) tem ensino superior completo e/ou pós-graduação, só este último representou 55,4\%, isto é, trinta e seis pessoas. De acordo com o Censo IBGE/2010, a porcentagem da população brasileira acima de dez ou mais anos de idade que tem ensino superior não ultrapassa os 8,3\%.

Outro questionamento que foi realizado a todos os sessenta e cinco entrevistados fazia referência a sua atuação na sociedade (Tabela 04), se era gestor(a) público, conselheiro(a) 
municipal (representante poder público), conselheiro(a) municipal (representante de entidades) ou membro da sociedade (não-conselheiro(a)). Vale lembrar que o objetivo da pesquisa é analisar a relevância/importância da participação popular nos CMAS pelas mais diversas visões.

Tabela 04: Papel exercido pelo respondente em relação ao CMAS

\begin{tabular}{|c|c|c|}
\hline & Frequência & Percentual \\
\hline Gestor(a) Público & 2 & $3,1 \%$ \\
\hline Conselheiro(a) municipal (representante poder público) & 3 & $4,6 \%$ \\
\hline Conselheiro(a) municipal (representante de entidades) & 1 & $1,5 \%$ \\
\hline Membro da Sociedade (não-conselheiro(a)) & 59 & $90,8 \%$ \\
\hline Total & 65 & $100 \%$ \\
\hline
\end{tabular}

Fonte: dados da pesquisa.

A pesquisa alcançou em sua grande maioria (cinquenta e nove participantes) membros da sociedade civil que não atuam como gestor público nem como conselheiros, o que representou 90,8\% das entrevistas. As demais categorias obtiveram 3,1\% para gestor público, 4,6\% para conselho municipal indicado pelo poder público e 1,5\% de conselheiro municipal representante de entidades.

O questionamento seguinte foi em relação a profissão dos pesquisados, por meio de uma pergunta aberta. Diante disso, as profissões mais recorrentes foram: advogado(a) (dezoito vezes), assistência social (quinze vezes), professor(a) (oito vezes), estudante (quatro vezes) e servidor(a) público(a) (três vezes). Entre as demais profissões dos respondentes, algumas haviam ligação direta com a temática, como: sociólogo, presbítero e associado de uma entidade de educação e assistência social

Tendo por base os dados apresentados sobre o perfil dos respondentes, o próximo tópico focará na análise da percepção desses entrevistas sobre a participação popular nos Conselhos Municipais de Assistência Social.

\section{Percepção dos entrevistados sobre a participação popular nos Conselhos Municipais de Assistência Social - CMAS}

Essa seção apresenta os resultados das questões específicas da pesquisa, com respostas obrigatórias, no que se refere a importância da participação popular nos CMAS. Na Tabela 05 
são expostos os resultados dos respondentes que conheciam algum Conselho Municipal de Assistência Social - CMAS.

\section{Tabela 05: Conhecimento sobre CMAS}

\begin{tabular}{|c|c|c|}
\hline & Frequência & Porcentagem \\
\hline Sim & 43 & $66,2 \%$ \\
\hline Não & 22 & 33,8 \\
\hline Total & 65 & $100 \%$ \\
\hline
\end{tabular}

Fonte: dados da pesquisa.

Conforme dados da Tabela 05, grande parte dos entrevistados (quarenta e três, isto é, $66,2 \%$ do total) afirmou que conhece algum Conselho Municipal de Assistência Social. Entretanto, por outro lado, um número considerável (vinte e dois pessoas $=33,8 \%$ ) informaram que não conhecem nenhum CMAS. Este dado é preocupante, uma vez que representa a longa caminhada que a democracia no Brasil ainda tem por trilhar. Até porque, somente com todos os canais democráticos criados pela CF/88 consolidados é que se poderá afirmar que em solo brasileiro há uma democracia efetivamente democrática.

No questionamento seguinte, conforme a Tabela 06, em relação a participação ou acompanhamento das reuniões de algum CMAS o índice obtido confirma a percepção inicial de que a participação popular é baixa, mesmo que o índice de participação ou acompanhamento das reuniões de algum CMAS possa ter sido considerável (nove pessoas, isto é, 13,8\% do total), uma vez que, uma parcela dos respondentes do estudo está ligada ao serviço social e a assistência social.

\section{Tabela 06: Participação ou acompanhamento das reuniões de algum CMAS}

\begin{tabular}{|c|c|c|}
\hline & Frequência & Porcentagem \\
\hline Sim & 9 & $13,8 \%$ \\
\hline Não & 56 & $86,2 \%$ \\
\hline Total & 65 & $100 \%$ \\
\hline \multicolumn{2}{|c|}{ Fonte: dados da pesquisa. } \\
\hline
\end{tabular}

Dentre o total de respondentes, nove participantes responderam sim à participação ou ao acompanhamento de reuniões de algum CMAS, assim outra questão foi investigada, o tempo 
de participação ou acompanhamento das reuniões. Foram obtidas as seguintes respostas: quatro meses de participação: 11,1\% dos respondentes, 1 anos: 22,2\%, 3 anos: 22,2\%, quatro anos: $11,1 \%$, seis anos: $11,1 \%$, sete anos: $11,1 \%$ e dez anos: $11,1 \%$.

Quando questionados sobre o interesse em conhecer ou participar de algum CMAS, a maioria $(69,2 \%)$ dos respondentes afirmaram que tem interesse, conforme pode ser observado na Tabela 07.

\section{Tabela 07: Interesse em conhecer e/ou participar de algum CMAS}

\begin{tabular}{|c|c|c|}
\hline & Frequência & Porcentagem \\
\hline Sim & 45 & $69,2 \%$ \\
\hline Não & 20 & $30,8 \%$ \\
\hline & & \\
\hline Total & 65 & $100 \%$ \\
\hline
\end{tabular}

Fonte: dados da pesquisa.

Como na análise de outros dados dessa pesquisa, aqui pode-se chegar ao mínimo-duas interpretações. Por um lado, o alto interesse (quarenta e cinco pessoas, isto é, 69,2\% do total de entrevistados) em conhecer/participar de algum CMAS é interessante e, diante disso, a construção e publicação de estudos como este são essenciais no auxílio a esta participação.

Por outro lado, o número de pessoas desinteressadas em conhecer e/ou participar de algum CMAS (vinte pessoas, o que representa $30,8 \%$ do total de entrevistas) é preocupante. Ainda mais se considerar que o Brasil ainda está caminhando no processo democrático. Afinal, desde a promulgação da CF/88 se passaram apenas trinta anos, se comparado ao último período de ditadura militar que durou vinte e um anos de retrocessos de quase a totalidade de direitos individuas e sociais.

O Gráfico 01, abaixo, oriundo do questionamento da pesquisa que teve por finalidade mensurar a importância que a participação popular desempenha nos Conselhos Municipais de Assistência Social sob a percepção dos respondentes, demostra que a maioria (60\%) atribui importância máxima da participação popular nos CMAS. 


\section{Gráfico 01: Grau de relevância da participação popular nos CMAS}

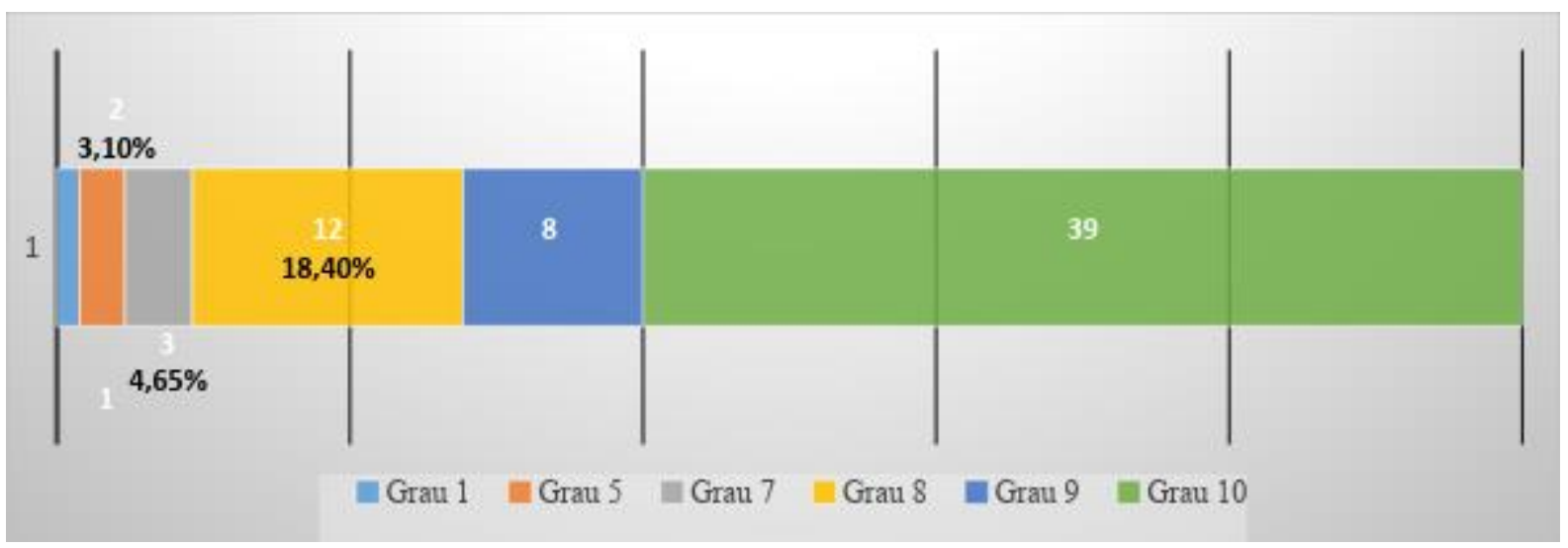

Fonte: dados da pesquisa.

Dessa forma, a partir da análise do Gráfico 01, é possível perceber que, do total de sessenta e cinco respondentes, trinta e nove (60\%) consideraram como grau máximo e vinte e três (35,35\%) avaliaram como grau alto (acima de 7 ) a relevância/importância da participação popular nos CMAS. Somando os graus máximo e alto, obteve-se o montante de 95,35\% do total de respondentes. Deixando apenas 4,6\% para grau baixo (uma resposta grau 1 (1,55\%) e duas, grau $5(3,10 \%)$.

Com relação as questões que versavam sobre as dificuldades para a participação popular nos CMAS; medidas/ações deveriam ser tomadas para ampliar a participação popular nos CMAS e; avaliação da atuação dos CMAS sobre a publicação das informações das reuniões, essas não tinham obrigatoriedade de resposta, com exceção da última que fazia referência a importância dos CMAS quando considerados como espaços para o exercício da cidadania. Dessa forma, a fim de apresentar os principais resultados desses questionamentos, as respostas foram agrupadas por semelhança de conteúdo e estão expostas sequencialmente conforme a ordem acima descrita.

No que tange as maiores dificuldades para a participação popular nos CMAS, dentre as respostas semelhantes e com maior incidência foi a falta de tempo, falta de informação e a própria participação popular. Entre as respostas com conteúdo mais detalhado, chamaram a atenção as seguintes : "Tempo e também talvez não seja uma prioridade, pois muitas vezes não se entende a importância dessa instância representativa" (RESPONDENTE 7). "O conselho de minha cidade acontece às $14 \mathrm{~h}$ da quarta-feira, e isso dificulta para trabalhadores/as que não conseguem dispensa nesses horários. Talvez também ocorram problemas com a mobilização da

\footnotetext{
${ }^{3}$ As respostas não são identificáveis, por razões éticas relacionadas ao estudo.
} 
própria comunidade, ou da maneira como as reuniões se estruturam, fazendo com que o espaço de torne desinteressante e não resolutivo para com as questões do SUAS no município" (RESPONDENTE 23).

Diante dos relatos sobre a falta de tempo para a participação nos conselhos municipais Santos e Avritzer (2003) lembram que há a necessidade do estabelecimento de novos vínculos de interação entre cidadão-cidadão e cidadão-Estado nas comunidades com a finalidade de afastar o atual cenário de desinteresse em relação ao que é comum, isto é, ao espaço público. Somente com ações concretas por parte do poder público, atreladas ao desenvolvimento da consciência participativa por parte dos cidadãos, é que se atingirá a participação nos centros decisórios das comunidades, como aqui é o caso dos CMAS.

Com relação as medidas/ações deveriam ser tomadas para ampliar a participação popular nos CMAS. A grande maioria das respostas passou por uma maior divulgação. Destacase o escrito do respondente 06: "disseminar o que é esse espaço, o que ele representa para a população, mostrando a importância dele para as ações da política de assistência social do município; e mais transparência, divulgação da importância, atribuições, trabalho desenvolvido do CMAS, fazendo com que a sociedade tenha interesse em participar".

Na ampliação da participação popular nos CMAS o governo local possui um papel de extrema importância, ao pensar e executar medidas/ações internas visando uma maior visibilidade para a sociedade desses centros decisórios (ORDÓÑEZ, 2005), como por exemplo, com a criação de sites/blog que objetivam a divulgação dos trabalhos realizados, datas das reuniões, pautas mensais, entre outros.

Quanto a avaliação da atuação dos CMAS, especialmente na publicação das informações das reuniões, as respostas mais triviais foram em relação a atuação do CMAS é de grande importância, porém fraca, restrita e/ou quase nula na sociedade atual.

Entre as respostas que aprofundaram, encontra-se: "avalio que são muito precárias, e que esse não é um debate aberto na comunidade. Penso que isso possa ser, de certa forma, estratégico, pois ao não divulgar essas informações, muitas decisões são tomadas de cima para baixo, mesmo sem consentimento de todos os conselheiros ou conhecimento da sociedade" (RESPONDENTE 20). E, "atuação modesta, funcionando mais como cumprimento de protocolo (formalidades legais) do que como fiscalizador e elaborador de Políticas Públicas" (RESPONDENTE 22).

Uma ferramenta importante de auxílio na divulgação das informações sobre as reuniões, tanto o calendário de reuniões como os assuntos que foram pautas nos encontros 
anteriores, são as redes sociais e a própria rede mundial de computadores. Grande parte dos conselhos municipais acabam não utilizando as novas tecnologias a seu favor, seja por desinteresse ou desconhecimento.

E, por fim, no que se refere ao questionamento das considerações dos participantes sobre os conselhos municipais apresentarem-se como espaços importantes para o exercício da cidadania e o motivo dessa relevância, quase a totalidade das respostas perpassaram pela afirmação para a importância. Mas algumas delas, são importantes para o fechamento da análise dos resultados, quais sejam: "Os conselheiros devem ser mais capacitados, e ter posicionamentos críticos. Só assim que conseguem exercer de fato a cidadania. Mas é um processo em disputa permanente. Mas quando ele não exerce sua autonomia fica como espaço só gerencial" (RESPONDENTE 15). "Na teoria os conselhos efetivamente seriam um importante órgão de controle social da administração pública e das políticas implementadas pelo governo. Mas na prática ainda é necessário um maior amadurecimento político, bem como ampliação da atuação dos conselhos com vinculação do chefe do executivo as decisões e pareceres" (RESPONDENTE 18).

Portanto, a participação popular, classificada por Souza (2014) como o fundamento para qualquer democracia contemporânea, acaba por possibilitar a reflexão e o enfrentamento pelos atores sociais das demandas sociais que estão próximas de cada realidade, renovando e reinventando-se diariamente. Ao transformar-se em uma questão social, a participação dos indivíduos confirma-se como o núcleo central das comunidades e o elo harmônico entre o Estado e o mercado.

\section{CONSIDERAÇÕES FINAIS}

Diante da conjuntura atual de crise estatal e da crescente demanda social por respostas aos problemas sociais que a cada dia apresentam-se de forma mais complexa e multicausal, privilegia-se o debate sobre modelos institucionais desafiadores, à exemplo disso, a participação social na gestão pública municipal como processo democrático de construção de políticas públicas no espaço público com vistas a promover o capital social local. Essa construção perpassa pela ampliação da importância dos conselhos municipais no poder local, na gestão pública municipal e na consolidação da democracia participativa, enquanto requisitos para o pleno desenvolvimento social e uma real condição de exercício da cidadania. 
Tem-se o espaço público local como um importante cenário para a garantia da atuação da sociedade civil e da comunidade, na perspectiva como ela deveria ser, capaz de impulsionar ações com o intuito de sanar dificuldades na participação social e da democracia participativa decorrente da complexidade e da contemporaneidade da sociedade e dos reflexos perversos da globalização. Além disso, verifica-se que os CMAS são fundamentais para a efetivação das políticas públicas em âmbito local, tendo em vista sua autonomia e a aproximação com os cidadãos a que se destinam.

O presente estudo teve como objetivo geral a verificação da importância da participação popular na gestão pública municipal, por meio dos Conselhos Municipais de Assistência Social, na promoção da democracia participativa no espaço público local. Essa participação social na construção de políticas públicas deve ser compreendida com o auxílio do poder local enquanto órgão próximo ao cidadão e com maior aderência às suas demandas.

De modo específico, estudou-se o poder local na (re)construção dos espaços públicos, delinearam-se os desafios e as perspectivas da participação popular na gestão pública municipal e, por fim, verificou-se a percepção da sociedade civil sobre a importância, ou não, da participação nos Conselhos Municipais de Assistência Social.

Dessa forma, o objetivo principal foi alcançado, uma vez que 95,35\% dos respondentes atribuíram grau alto e máximo com relação a importância da participação popular por meio dos CMAS. Com relação ao primeiro objetivo específico, este foi alcançado no levantamento bibliográfico realizado em relação ao poder local enquanto marco de reconstrução dos espaços públicos nas sociedades contemporâneas.

Na sequência, o segundo objetivo especifico foi alcançado, uma vez que delineou os desafios e as perspectivas da participação popular na gestão pública municipal. Em relação aos desafios para a implementação de uma nova cultura de democracia participativa na construção de políticas públicas por meio dos Conselhos Municipais, deve-se constituir e trabalhar levando em consideração toda a diversidade existente no espaço público. No que se refere as perspectivas futuras, em um cenário de globalização sinônimo de individualização e perversidade não são apresentadas de maneira promissora, uma vez que, diariamente a participação popular nos Conselhos Municipais encontra novos entraves.

O terceiro objetivo inicialmente traçado foi alcançado no momento da análise dos dados oriundos do questionário online aplicado a sessenta e cinco pessoas referente a importância da participação popular nos Conselhos Municipais de Assistência Social - CMAS como contributo a democracia participativa. Da percepção dos participantes e dos dados 
levantados, foi possível concluir que os Conselhos tem por finalidade aproximar os cidadãos dos problemas enfrentados pelos municípios e, com isso, oportunizar a colaboração na construção, formulação e implementação de políticas públicas.

O sucesso de uma política pública em nível local, em razão da delimitação espacial deste estudo, pode ter como um dos fatores a qualidade da adequação e de sua fiscalização/avaliação. Nesse cenário, os CMAS podem ser compreendidos como um canal aberto entre a população e o poder público, com o objetivo de possibilitar a escuta da sociedade a partir de suas próprias realidades sociais.

Portanto, demonstrou-se a importância da participação popular na gestão pública municipal a partir dos Conselhos Municipais de Assistência Social enquanto política pública de aperfeiçoamento da democracia participativa no espaço público local, entretanto, que ainda há um caminho muito longo a ser trilhado em sua consolidação. Ao mesmo tempo que, apresentase como um mecanismo de alteração do atual contexto de descrédito no Estado e nos processos de globalização a partir de seus reflexos negativos às relações sociais.

Há a necessidade essencial de se alterar o cenário mundial da globalização que perpassa pelo aperfeiçoamento da convivência em comunidade, isto é, para que essa grande alteração seja efetiva, deve-se iniciar na comunidade, no município, no local mais próximo ao cidadão, pois somente o indivíduo emancipado e conhecedor, tanto da sua realidade quanto da possibilidade de transformação, será capaz de fomentar e de promover a mudança que as sociedades necessitam para continuar se desenvolvendo. Esse desenvolvimento perpassa pela participação popular na gestão pública municipal por meio dos Conselhos Municipais de Assistência Social enquanto política pública de aperfeiçoamento da democracia participativa no espaço público.

O estudo verificou a percepção das pessoas sobre a importância da participação popular nos Conselhos Municipais de Assistência Social por meio de um questionário online disponibilizado entre os dias 16.05 .2018 e 27.05.2018. Esse espaço de tempo razoavelmente curto, atrelado a limitação de verificação afundo de tal temática em razão do instrumento ser aberto com questões em sua grande maioria fechada ou direcionadas, pode ter produzido respostas limitadas.

Diante disso, têm-se como sugestão para estudos futuros a análise da participação popular a partir de uma verificação in loco nos Conselhos Municipais, inclusive com entrevistas com gestores municipais, conselheiros e membro da sociedade civil que participam ativamente, bem como com o acompanhamento de reuniões dos CMAS. 


\section{REFERÊNCIAS}

ANDUIZA, E.; BOSCH, A. Comportamiento político y electoral. 2. ed. Barcelona: Ariel, 2007. ARISTÓTELES. Política. Brasília: Universidade de Brasília, 1985.

BEHRING, E. R.; BOSCHETTI, I. Política Social: fundamentos e história. 9. ed. São Paulo: Cortez, 2011. v. 2.

BONAVIDES, P. Teoria constitucional da democracia participativa. 3. ed. São Paulo: Malheiros, 2008.

BRASIL. Lei n. 8.742 de 07 de dezembro de 1993. Dispõe sobre a organização da Assistência Social e dá outras providências. Disponível em: <www.planalto.gov.br/ccivil_03/Leis/L8742compilado.htm>. Acesso em: 25 mai. 2018.

BRASIL. Portal da Transparência. Controle Social: conselhos municipais e controle social. [s.d.]. Disponível em: <www.portaldatransparencia.gov.br/controlesocial/ConselhosMunicipaiseControleSocial.asp>. Acesso em: 25 mai. 2018.

CORRÊA, D. Estado, cidadania e espaço público: as contradições da trajetória humana. ljuí: Ed. Unijuí, 2010.

DEMO, P. Participação é conquista. São Paulo: Cortez, 1988.

DIAS, S. G. Reflexões acerca da participação popular. Revista Integração, São Paulo a. 13, n. 48, p. 48-53, jan./mar. 2007.

DIEHL, R. C.; COSTA, M. M. M. O papel da comunidade na pacificação de conflitos. Curitiba: Multideia, 2015.

DOWBOR, L. O que é poder local? São Paulo: Brasiliense, 2008.

FONSECA, J. J. S. Metodologia da pesquisa científica. Fortaleza: UEC, 2002.

FOUCAULT, M. Microfísica do poder. Rio de Janeiro: Edições Graal, 2009.

GARRISON, J. W. Do confronto à colaboração. Relações entre a sociedade civil, o governo e o banco mundial no Brasil. Brasília: Banco Mundial, 2000.

GERHARDT, T. E.; SILVEIRA, D. T. (Org.). Métodos de pesquisa. Porto Alegre: Ed. da UFRGS, 2009. GOHN, M. da G. Os conselhos municipais e a gestão urbana. In: SANTOS JR, O. A.; RIBEIRO, L. C. Q.; AZEVEDO, S. (Orgs.). Governança democrática e poder local: a experiência dos conselhos municipais no Brasil. Rio de Janeiro: Revan, 2004, p. 11-56.

GRÜNE, C. Participação cidadã na gestão pública. São Paulo: Saraiva, 2012. 
HERMANY, Ricardo. Município na Constituição: poder local no constitucionalismo luso-brasileiro. Curitiba: Juruá, 2012.

MACHADO, L. M. de O. Participação popular. In: FERNANDES, R. M. C.; HELLMANN, A. (Orgs.). Dicionário crítico: política de assistência social no Brasil. Porto Alegre: Ed. UFRGS, 2016, p. 183186.

MALHOTRA, N. Pesquisa de marketing: uma orientação aplicada. 4. Ed. Porto Alegre: Bookman, 2006.

MARKOFF, J. Democracia: transformações passadas, desafios presentes e perspectivas futuras. Revista Sociologias, Porto Alegre, a. 15, n. 32, p. 18-50, jan./abr. 2013.

MINAYO, M. C. S. O desafio do conhecimento. Pesquisa qualitativa em saúde. São Paulo: HUCITEC, 2007.

NEVES, Â. V. Cultura política e democracia participativa: um estudo sobre o orçamento participativo. Rio de Janeiro: Gramma, 2008.

ORDÓÑEZ, J. D. La participación ciudadana en el ejercicio de las funciones administrativas en el Perú. In: LEAL, R. G. (Org.). Administração pública e participação social na América Latina. Santa Cruz do Sul: Edunisc, 2005, p. 61-108.

PELUFFO, J. P. C. Poder público y participacion ciudadana en el derecho uruguayo. In: LEAL, R. G. (Org.). Administração pública e participação social na América Latina. Santa Cruz do Sul: Edunisc, 2005, p. 15-44.

SANTOS JR, O. A.; RIBEIRO, L. C. Q.; AZEVEDO, S. Democracia e gestão local: a experiência dos conselhos municipais no Brasil. In: SANTOS JR, O. A.; RIBEIRO, L. C. Q.; AZEVEDO, S. (Orgs.). Governança democrática e poder local: a experiência dos conselhos municipais no Brasil. Rio de Janeiro: Revan, 2004, p. 11-56.

SANTOS, B. S.; AVRITZER, L. Para ampliar o cânone democrático. In: SANTOS, Boaventura de Sousa (Org.). Democratizar a democracia: os caminhos da democracia participativa. 2. ed. Rio de Janeiro: Civilização Brasileira, 2003, p. 39-82.

SOUZA, M. L. de. Desenvolvimento de comunidade e participação. 11. ed. São Paulo: Cortez, 2014.

TOURAINE, A. Poderemos viver juntos? Iguais e diferentes. 2. ed. Petrópolis: Vozes, 1998.

TRIVIÑOS, A. N. S. Introdução à pesquisa em ciências sociais: a pesquisa qualitativa em educação. São Paulo: Atlas, 1987.

VIEIRA, L. Os argonautas da cidadania: sociedade civil na globalização. Rio de Janeiro: Record, 2001.

Revista de Direito da Cidade, vol. 11, no 1. ISSN 2317-7721 pp. 682-710 
Revista de Direito da Cidade

vol. 11, no 1. ISSN 2317-7721

DOI: $10.12957 /$ rdc.2019.36644

Trabalho enviado em 11 de agosto de 2018

Aceito em 09 de setembro de 2018

Revista de Direito da Cidade, vol. 11, no 1. ISSN 2317-7721 pp. 682-710

710 